\title{
OSTEOPLASTIC THORACOPLASTY
}

\author{
BY \\ SIR RUSSELL BROCK \\ From Guy's Hospital and the Brompton Hospital, London
}

(RECEIVED FOR PUBLICATION JANUARY 26, 1955)

During the past eight years (since March, 1947) I have been using a modified thoracoplasty which has stood the test of time sufficiently to justify publication. I had had the operation in mind for several years before this but had not had the courage to use it, for the actual step of cutting an osteoplastic flap from the ribs and sewing it over the mobilized lung to hold it down was rather intimidating. However, the difficulties encountered have not been great and the results have been encouraging.

\section{Advantages Claimed for the Operation}

There are certain objections to thoracoplasty in its various standard forms, whether it is used as direct treatment for pulmonary tuberculosis, or whether it is used to supplement lung resection.

The objections are chiefly related to the actual removal of ribs, with the attendant deformity, the need for multiple stages, and the extra danger, especially in poor-risk cases, of paradoxical respiration after operation when the support of the ribs is lost. Although the deformity can be lessened by careful physical treatment so as to be almost imperceptible, it may be very noticeable, especially from the cervico-thoracic scoliosis and rotation of the head and neck; this is an important drawback in thinly covered women, and particularly so in young women.

A chronic fibrocavernous lung lesion with tough extrafascial adhesions and contracted overlying ribs, if a collapse procedure is needed, usually requires one of the standard forms of thoracoplasty, preferably with the Semb apicolysis. There are, however, other cases with less disease in which a lesser procedure may be possible. Mobilization of the lung can be achieved by extrapleural, or part extrapleural and part extrafascial, apicolysis, and the lung can then be held down by an osteoplastic flap consisting of segments of the third and fourth ribs. The lung is given immediate support and there is no risk of paradoxical respiration. As the only alteration of the thoracic cage is displacement of the segment of the third and fourth ribs, there is no external deformity; the conservation of the first two ribs is especially valuable, as it avoids an ugly depression below the clavicle and also prevents the disfiguring cervico-thoracic scoliosis.

In an attempt to overcome the disadvantages of ordinary thoracoplasty a number of surgeons have reintroduced the principle of the insertion of a plombe of foreign material between the ribs and the lung after it has been mobilized. The availability of modern plastic substances has encouraged these attempts in the belief that the body is more tolerant of them than it was of paraffin wax or "gomenol" and olive oil in the days when these were popular. Time alone will tell how long the presence of such foreign materials will be tolerated by the body. Fundamentally the surgeon should be uneasy about their use and their presence in the body, even though the new plastics may seem to be better tolerated.

The osteoplastic thoracoplasty described here aims at giving an equal degree of collapse with immediate stability and without the dangers and disadvantages of introducing foreign substances ; the collapse is achieved by a simple displacement of the living tissues of the body.

Some other surgeons have used various osteoplastic modifications of thoracoplasty (Eloesser, 1942 ; Overholt and Kenney, 1951 ; Björk, 1954), but none uses a comparable osteoplastic flap.

\section{Selection of Cases for Operation}

The present success of lung resection in all its forms for pulmonary tuberculosis has led to far fewer collapse operations being done, except as supplementary to resection. Osteoplastic thoracoplasty should be considered in any case in which permanent and selective collapse of a resistant upper-lobe lesion is needed, especially when the avoidance of deformity is important. As already stated, it is best not used when the upper lobe is contracted, fibrous, and with densely thickened pleural and extrafascial planes; nor is it indicated for collapse of the whole lung. Where a space- 
reducing procedure is needed after resection, osteoplastic thoracoplasty supplies this need excellently, as will be shown later. In fact its use in conjunction with resection has proved to be perhaps its most important application since the decline in favour of the pure collapse procedures. I have

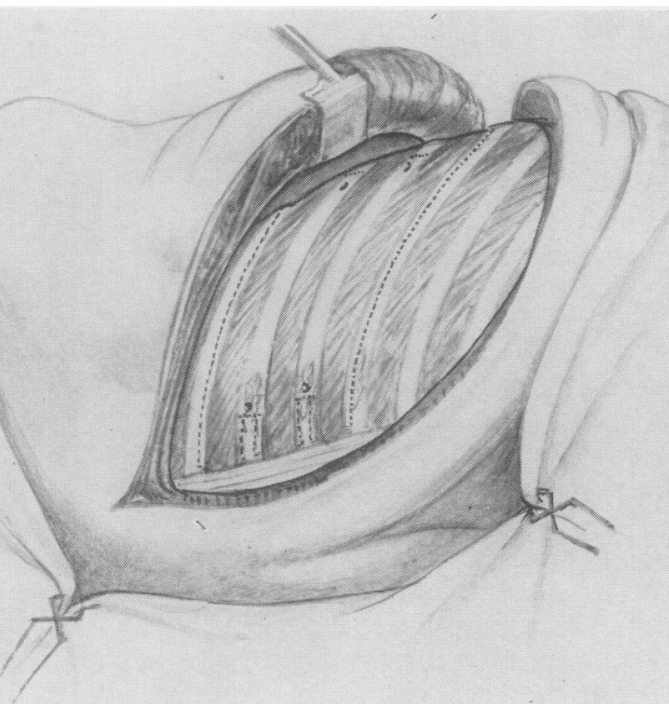

FIG. 1. The ribs have been exposed and the mode of cutting the osteoplastic flap is outlined. very high at the back. The musculoplastic modi $\overrightarrow{\vec{*}}$ fication already described (Brock, 1946) may be used with advantage. It is better not to incise an intercostal space but to strip the periosteum from the upper border of the fifth rib and the lowe border of the second rib. The intercostal bundles are thus stronger and their bloods supply less liable to be interfered with, and the extrapleural layer canbe easily entered by incising throughw the rib bed. Figs. 1 and 2 show the? outlines and the mode of formation $\vec{x}$ of the flap.

The extrapleural plane is enteredbelow and the lung is then freed downwards to the level of the sixth rib or interspace and upwards to the second rib or first interspace ; a the same time commensurate free ing will be done, behind into the paravertebral groove and well fore wards in front. As soon as the under surface of the third and fourth ribs has been freed it is an advans tage to make drill holes and divide the ribs. The drill holes are simplso

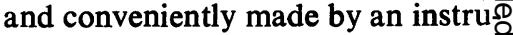
ment shown in Fig. 3 and specially also used it in a case which had been unsuccessfully treated by a plombage with plastic spheres and in which secondary lobectomy was needed.

\section{The Operation}

The principle of the operation is to perform the correct amount of extrapleural or extrafascial pneumonolysis (or a combination of both) and then hold the lung in the collapsed position by an osteoplastic flap composed of segments of the third and fourth ribs, with the intercostal muscles, vessels, and nerves preserved intact in front and behind so that the nutrition of the flap is unimpaired. The cut ends of the ribs in the flap are sewn behind to the anterior longitudinal ligament of the spine and in front to the rib cartilages.

The incision is the usual J-shaped posterior one for thoracoplasty except that it need not be carried

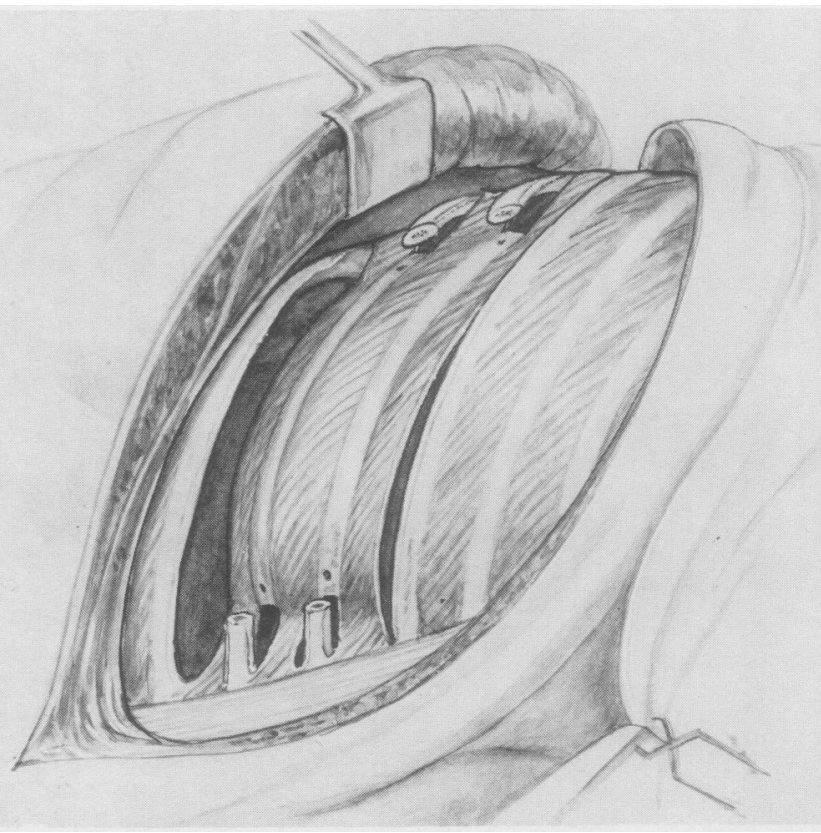

Fig. 2.-The flap has been cut and its construction can be appreciated. It consists of segmepts of the third and fourth ribs with the second, third, and fourth intercostal bundtes conserved intact both in front and behind. In this way nutrition of the flap is unimpaira. Note drill holes in ribs. 
made for me. This instrument has been used for some four years and has proved very useful.

Posteriorly the ribs are divided just in front of the angle; anteriorly about the mid-axilla. After

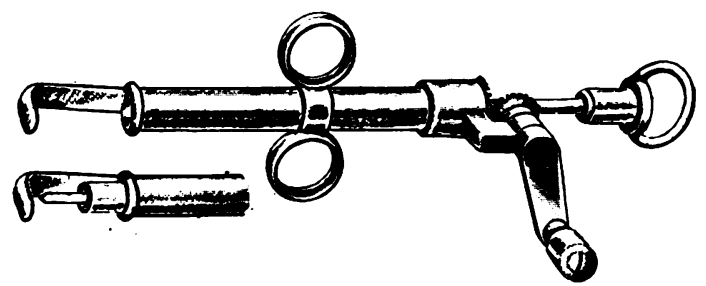

Fig. 3.-Rib drill (Genito-Urinary Manufacturing Company).

a little practice the necessary length can readily be estimated ; it is usually about 6 in. $(15 \mathrm{~cm}$.). If any doubt is felt about the site of anterior division, this can be deferred until after the lung has been freed and the exact distance measured from the spine to the costal cartilages. Once the ribs have been divided and the upper boundary of the flap defined by incising the periosteum in the lower part of the bed of the second rib, an excellent exposure of the interior of the chest is obtained, and the pneumonolysis can be completed with ease in the usual manner.

The flap is not yet sufficiently mobile to reach the lung in its collapsed position, but can easily be made so by freeing the periosteum, and hence the intercostal bundles, right back to the head of the ribs and a short distance in front. Judicious extra touches and freeing here and there will give full

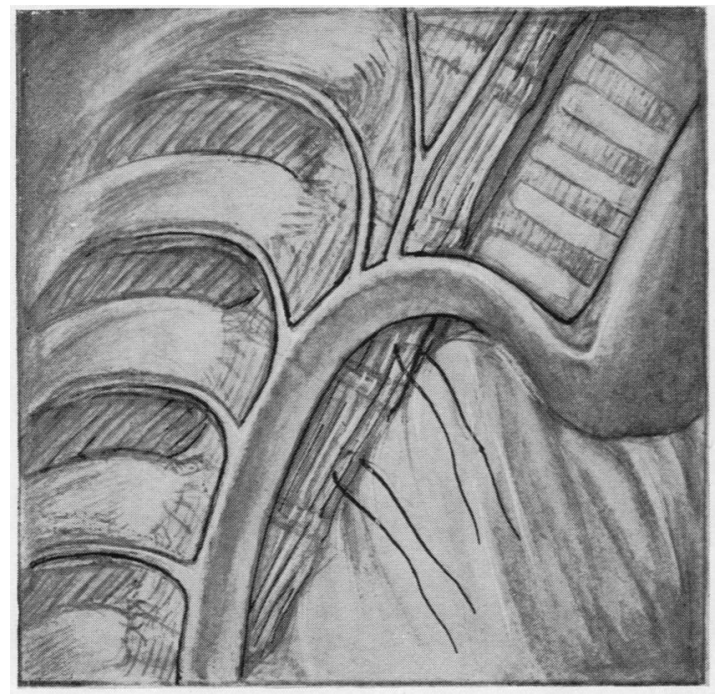

FIG. 4 mobility to the flap. As the rib segments must rotate medially as well as be displaced medially, it is necessary to incise the periosteal beds of the two divided ribs in the gaps in front and behind to allow the ends to rotate. If the stripping is done with due care the vessels and nerves in the intercostal bundles remain intact.

The flap must now be fixed in position. The posterior ends are sutured to the anterior longitudinal ligament; this is easily exposed by very little dissection, though care is needed to avoid puncturing the near-by veins. The third rib is fixed about $1.5-2 \mathrm{~cm}$. below the azygos arch, the fourth a short distance lower (Figs. 4 and 5). On the left side the fixation is made just above the aortic arch. I used to use stainless steel wire for the sutures (as indeed can be seen from the radiograph, Fig. 12), but I now use strong linen thread (No. 25). If the anterior longitudinal ligament is picked up boldly and cleanly by the needle a very strong fixation is secured. It is better to pass the stitches through the drill holes in the ribs and then to leave them untied until the anterior stitches are in place. This part of the operation will be found difficult with an ordinary needle, but is easy if a Harris's boomerang needle is used. The upper stitch is passed round the third cartilage just lateral to the internal mammary vessels and then through the drill hole in the third rib. The suture for the fourth rib is placed round the fourth costal cartilage. Sometimes the anterior end of the fourth rib can be left free.

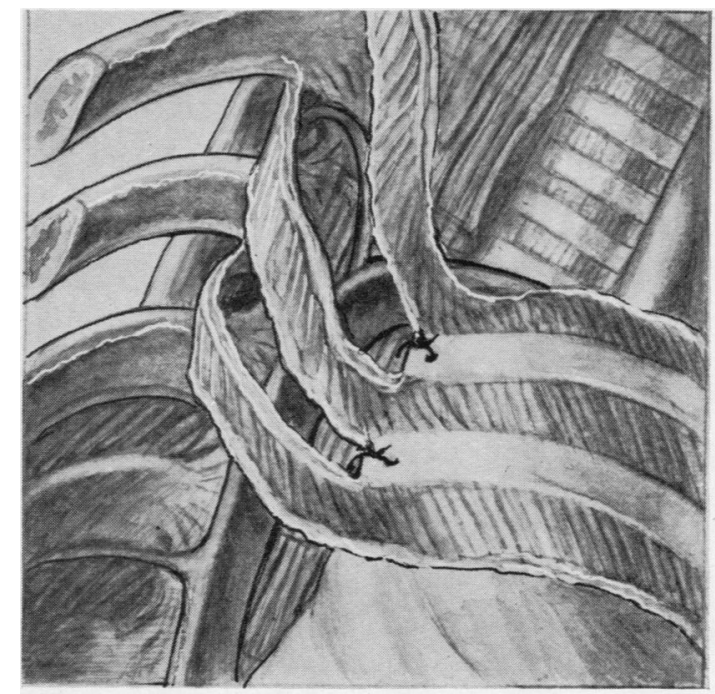

Fio. 5

FiGs. 4 and 5.-The mediastinal exposure after pneumonolysis and the mode of suture of the back ends of the ribs to the anterior longitudinal ligament of the spine. 
Once all the sutures have been inserted a final check is made of the disposition of the flap and the intercostal bundles (which should be quite free), before the sutures are tied. The flap will now be found to be firmly fixed, holding the mobilized lung down to the level of the hilum. The curve of the ribs reproduces the natural shape of the upper part of the normal thoracic cage, and it is almost as if a new bony apex has been fashioned to accommodate the upper lobe at its new level. This is well shown in the various radiographs.

The gap between the lower edge of the flap and the chest wall should now be loosely closed by inserting a few mattress

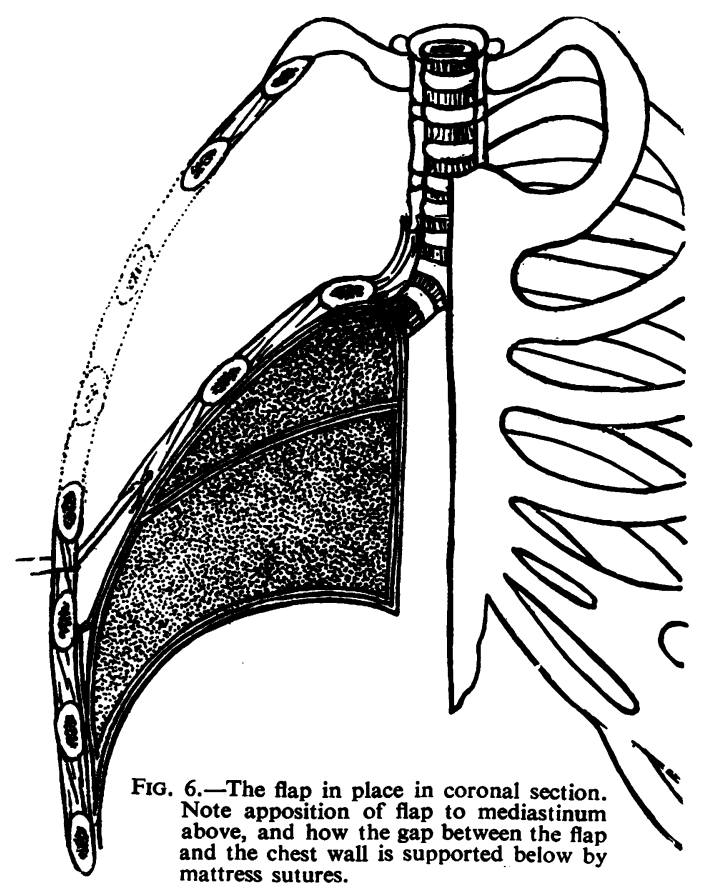

sutures from the fourith intercostal bundle (i.e., the lower fringe of the flap) the fifth intercostal spae (Fig. 6). Sometimes may be necessary to pla⿳⺈ a stitch or two aboge, between the second intercostal bundle (which forms the upper fringe of the flap) and the mediastinuक日, but usually this gap त्रेंs closed by simple apposition of the flap to the mediastinum.

The wound is closed without drainage, unless,

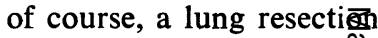
has been done.

In some of the earlier cases in which the lumg lesion was more extemsive and extended loty enough down to dema d a seven- or eight-ritb thoracoplasty, the mobilization was extend

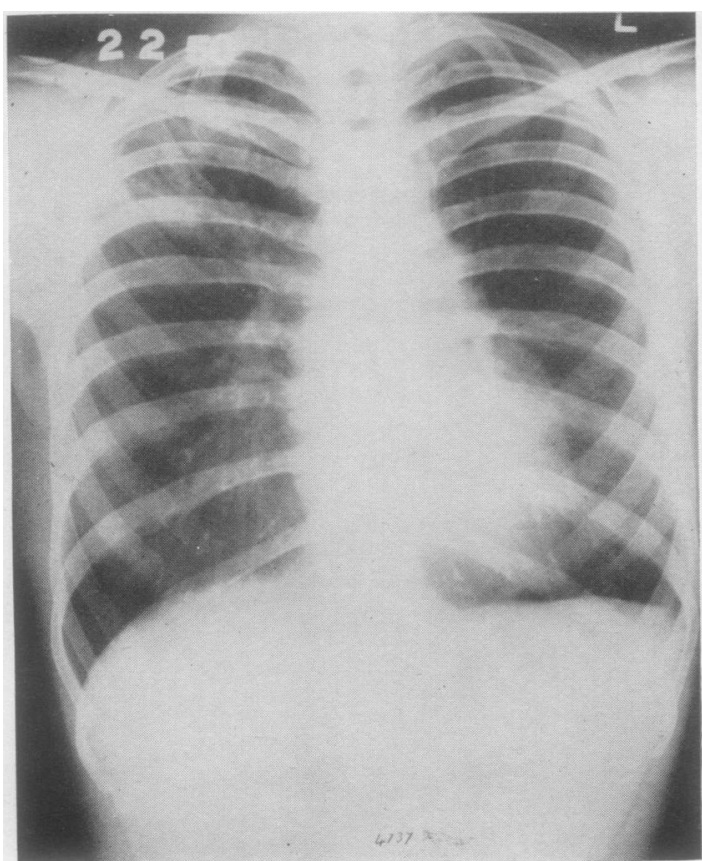

Fig. 7

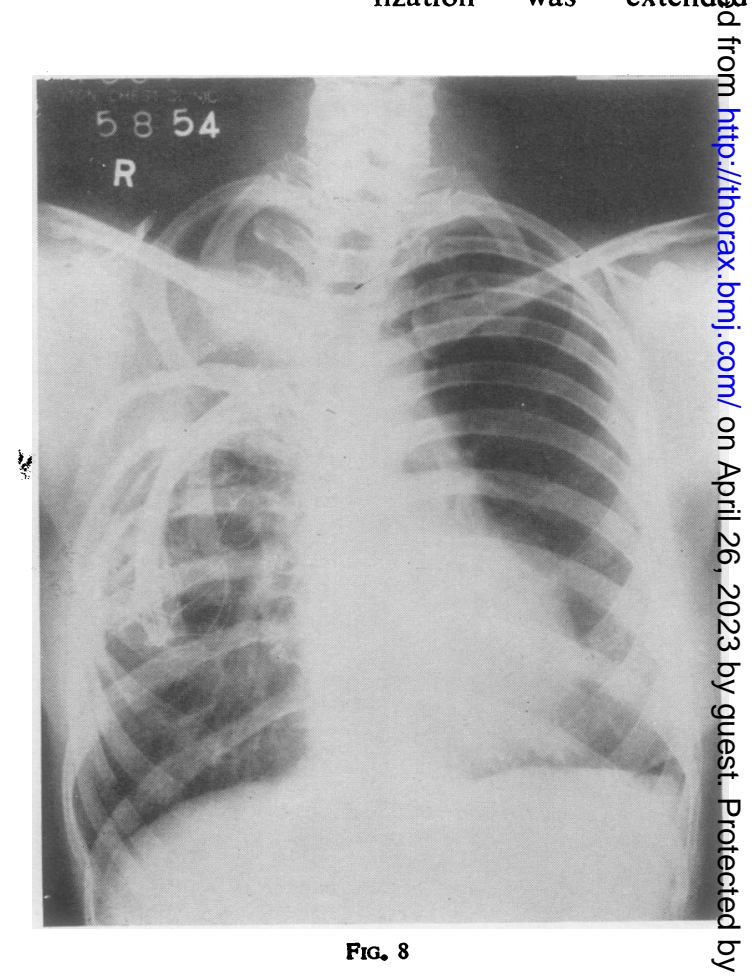

FIGs. 7 and 8.-Radiographs of a case in which extra collapse was obtained by extending the extrafascial and extraperiosteal mobiliz- $\cap$ ation downwards, the lower ribs $(6,7$, and 8$)$ being left in place. 

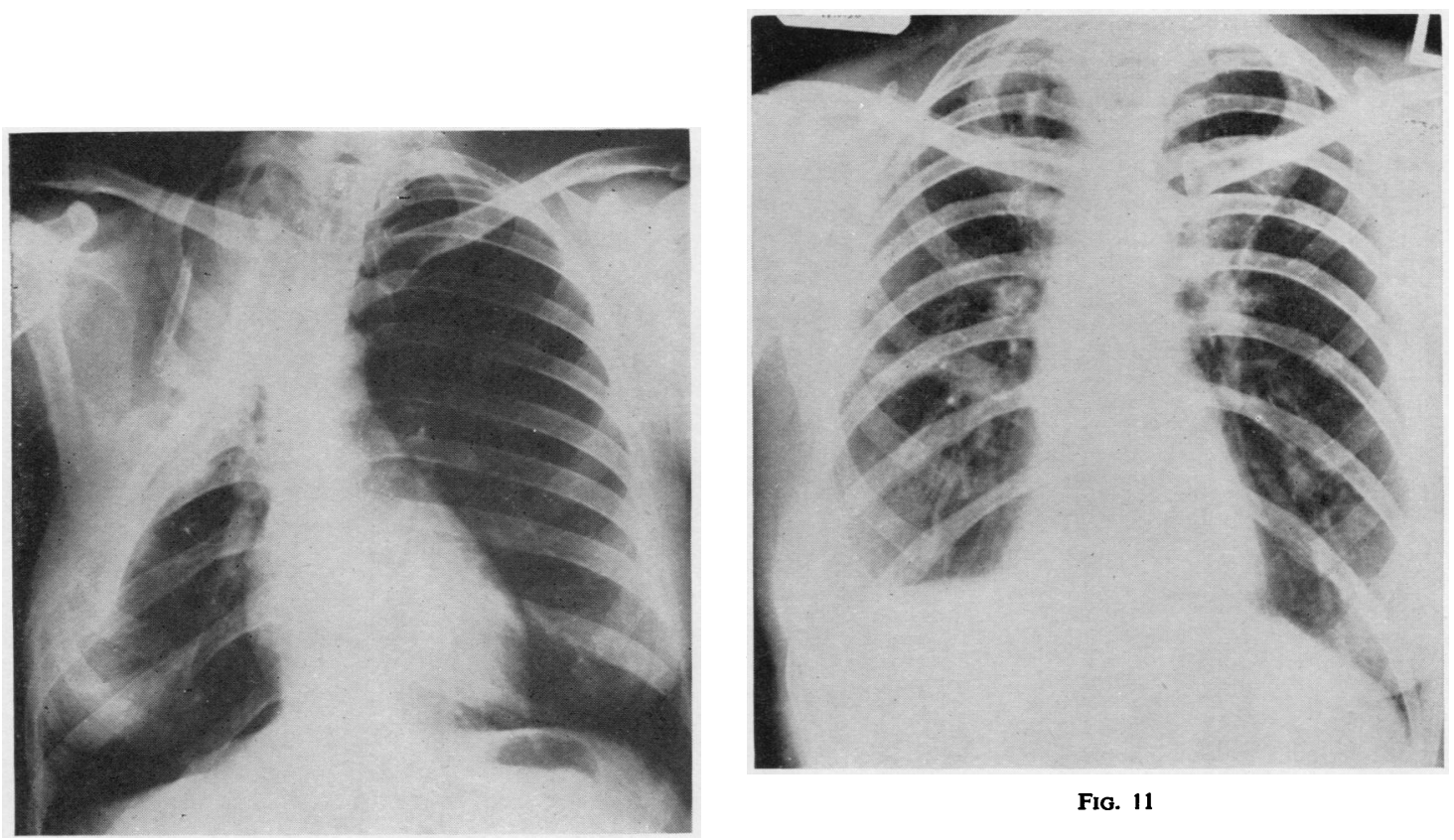

Fig. 9
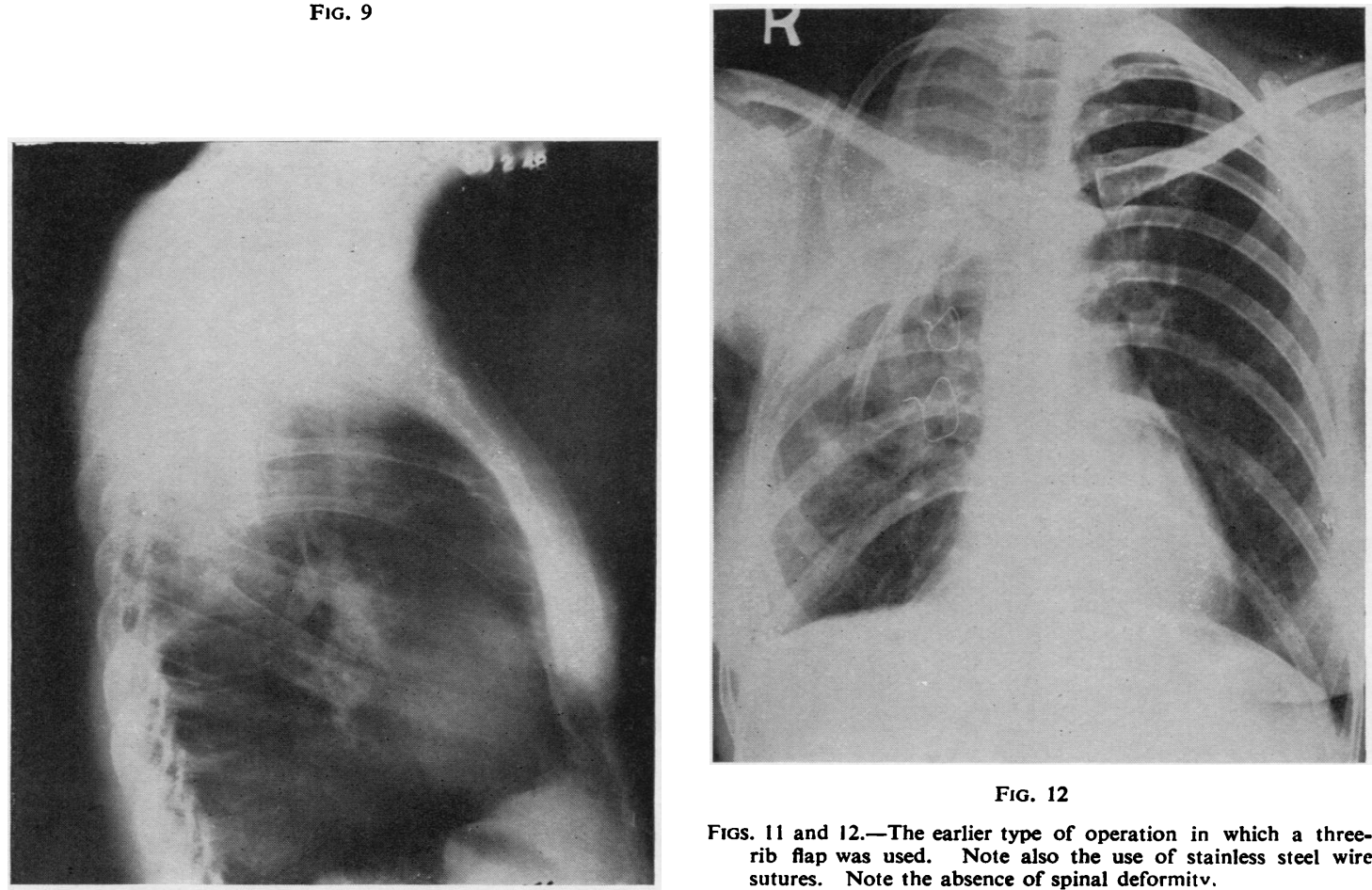

Fig. 12

FIGs. 11 and 12.-The earlier type of operation in which a threerib flap was used. Note also the use of stainless steel wire sutures. Note the absence of spinal deformitv.

Fig. 10

FiGs. 9 and 10.-Radiographs of two-stage-osteoplastic thoracoplasty. In such a case some thoracic scoliosis is inevitable. 
further down. This was achieved by stripping the sixth and seventh and, if necessary, the eighth ribs and mobilizing the intercostal bundles right back to the heads of the ribs so that a musculo-periosteal flap was formed and sank in (Figs. 7 and 8). This may be attached on a deeper plane by a few interrupted sutures. If necessary it can be performed as a second stage ; indeed, a second osteoplastic flap may be cut and sewn in place in a manner similar to the first flap if so wished (Figs. 9 and 10).

In the first case in which the operation was used a two-rib flap was cut, but the tissues were thin and the intercostal bundles were damaged, so that necrosis occurred and the flap had to be removed and a formal thoracoplasty substituted. After this three ribs (third, fourth, and fifth) were used so as to make a more stable flap, and there was no further trouble with nutrition (Figs. 11 and 12). However, the three-rib flap is not necessary and moreover may be a disadvantage in that a short scapula may just catch on the edge of the sixth rib. For some time now I have reverted to the original two-rib flap with complete satisfaction.

\section{Discussion AND Results}

When used as a supplement to lung resection the operation can be begun in a similar way by stripping the periosteum from the top border of the

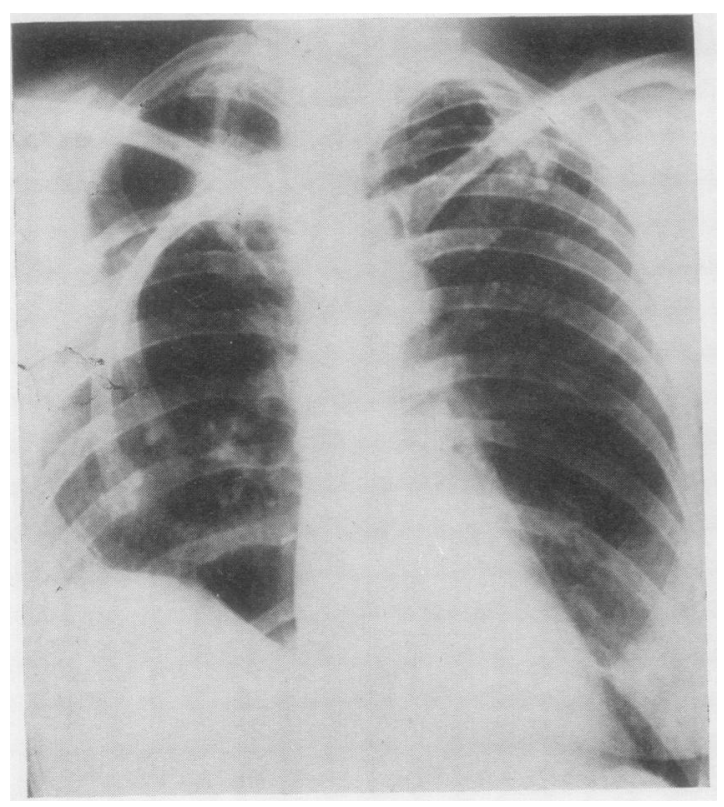

FIG. 13.-Osteoplastic thoracoplasty complementary to right upper lobectomy and resection of apical segment of lower lobe. fifth rib and incising through the rib bed ; division of the back end of the fifth rib will then allow the ribs to spread to give adequate exposure for resection. When the rib spreader is used care should be taken to evert the fifth intercostal bundle so that the vessels and nerves are not bruised. After the lung resection the flap is cut exactly as described and sewn in place. This gives a very satisfactory reduction of the hemithorax with immediate stability and support of the lung. The end-result can be seen in the radiograph in Fig. 13, in which a right upper lobectomy and resection of the apical segment of the lower lobe had been done.

It will be seen from the various radiographs that the mobilization and collapse of the lung is maintained absolutely and to a degree no less than is achieved by thoracoplasty. If relaxation and collapse are to secure healing of a lung lesion this should be attained by the operation. Indeed, collapse may easily be made too great, especially in front, where it should be remembered that the flap is fixed to the costal cartilages. It is to grade off the amount of anterior collapse that the lower rib is left free in front; the amount of anterior collapse can be further lessened by suturing the anterior ends of the ribs not so far medially as the costal cartilages.

Osteoplastic thoracoplasty has been used in 25 cases and the results are tabulated on page 8 .

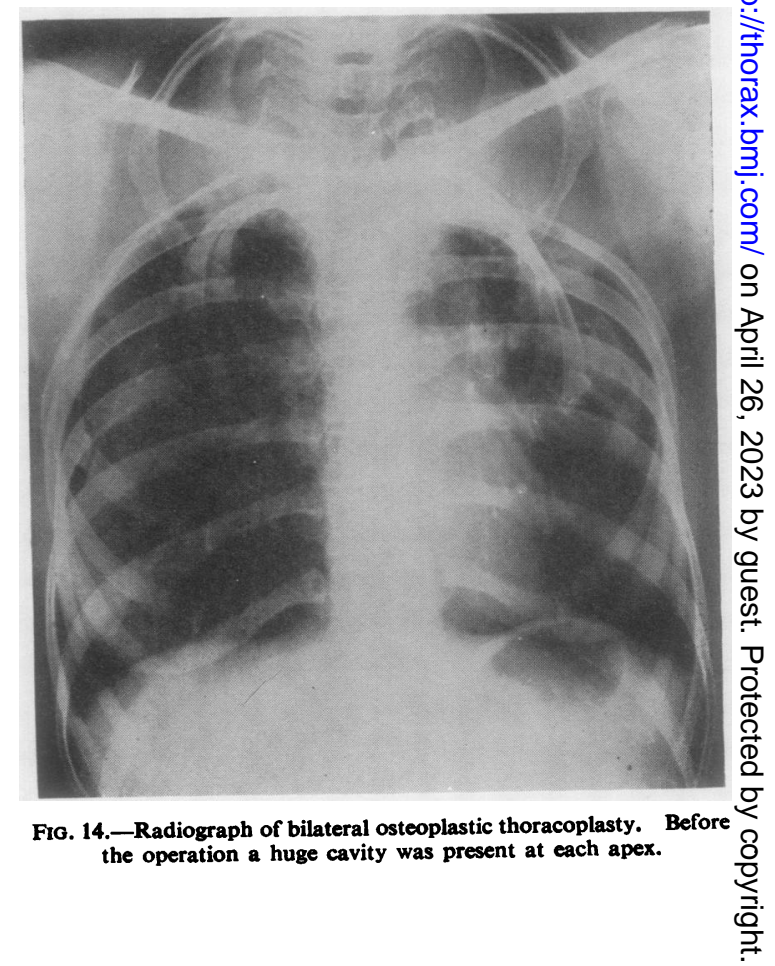




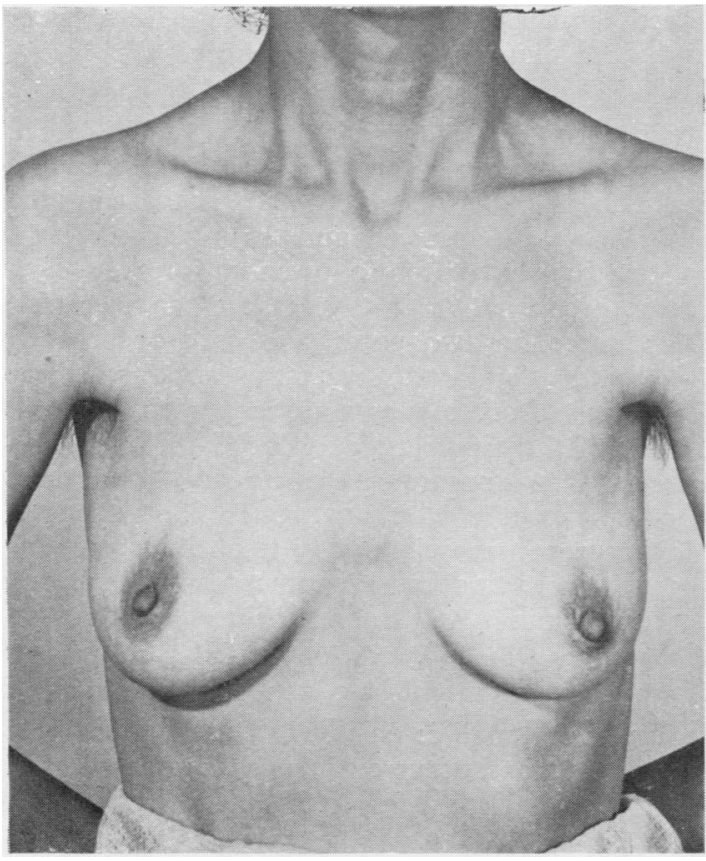

Fig. 15

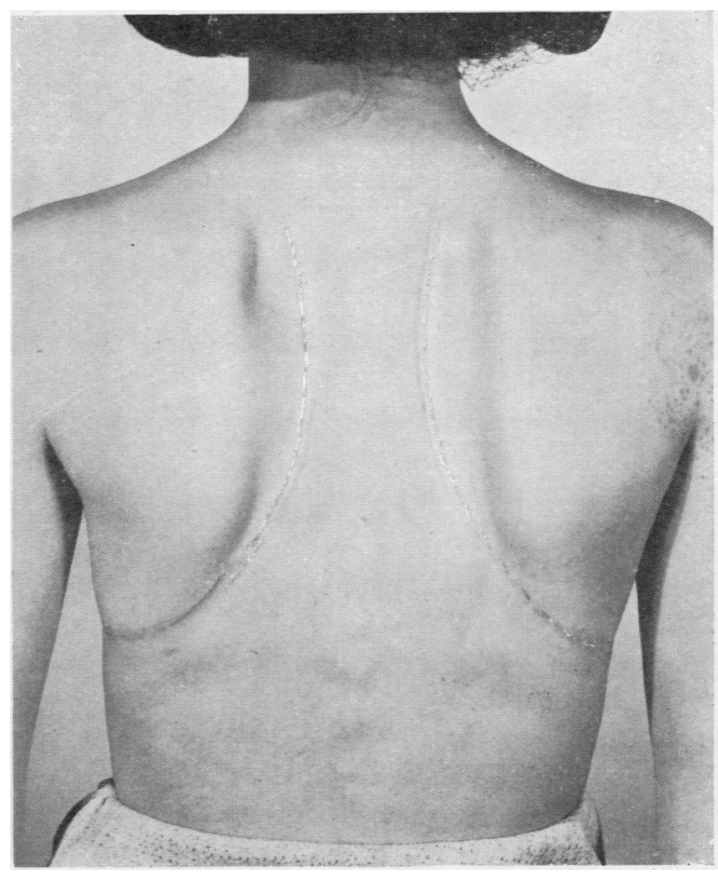

Fig. 16

Figs. 15 and 16.-After bilateral osteoplastic thoracoplasty, to show absence of external deformity.

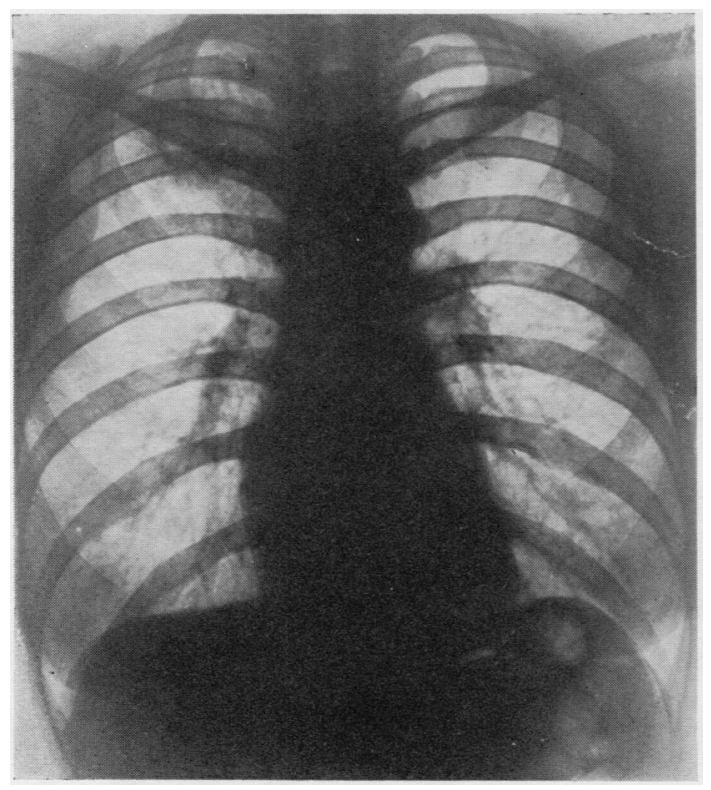

Fig. 17

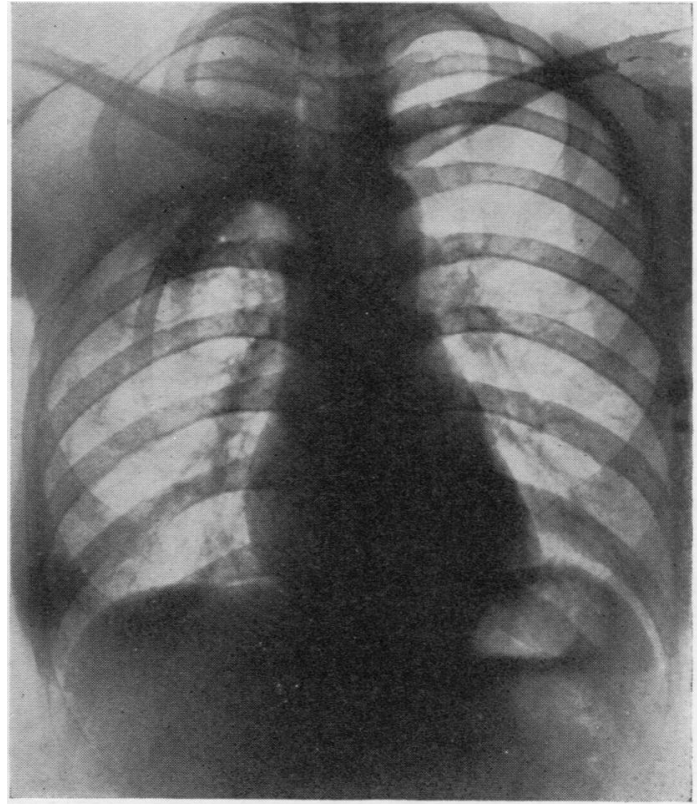

Fig. 18

FiGs. 17 and 18.-Radiographs before and after operation in which the present two-rib flap has been used. No wire sutures. Note absence of deformity. 


$$
\begin{array}{cccccc}
\multicolumn{6}{c}{\text { ReSUlts in } 25 \text { CASES* }} \\
\text { Total } \ldots & \ldots & \ldots & \ldots & \ldots & 25 \text { cases } \\
\text { Died } & \ldots & \ldots & \ldots & \ldots & 1 \\
\text { Failed } & \ldots & \ldots & \ldots & \ldots & 6 \\
\text { Good result } & \ldots & \ldots & \ldots & 18 \\
\text { Combined with resection } & \ldots & \ldots & 6 \\
\text { Bilateral } \ldots & \ldots & \ldots & \ldots & 1 \\
\text { *Longest follow-up is } 8 \text { years. }
\end{array}
$$

It will be observed that only one death occurred, and this was in an unfit woman aged 54 who also had a right upper lobectomy. In one patient the operation was used on both sides (Figs. 14-16) ; this patient originally had a large cavity in both upper lobes and was a very bad risk; the right side was operated on in May, 1947, nearly eight years ago, and the left side in October, 1947, seven and a half years ago. She remains well and does all her own housework and ordinarily has no cough or sputum, though occasionally she produces a trace of sputum, which has been positive at times.

In six cases the operation has been combined with lung resection and has given complete satisfaction except in the one death.

In six cases it failed, and the patient has either been left alone or a secondary resection has been done. The failures were really due to faulty selection in the first instance, although this was perhaps excusable because they were all cases carrying a very bad risk in whom it had been hoped to gain control of the disease by a lesser procedure than formal thoracoplasty.

In 18 cases (including five resections) the results have been good and have remained good. A very gratifying thing has been the excellent cosmetic result. This is well shown in the bilateral case (Figs. 15 and 16). Of these $18 \mathrm{c}$ patients four have been followed up for over seven $\vec{\circ}$ years, three for over five years, six for over four $\vec{\exists}$ years, three for two years, and two for between 18 months and two years. Certainly there seems no reason to expect any complication from $\times$ the use of the osteoplastic flap itself. Figs. 17 and $\vec{\circ}$ 18 show the appearance before and four years after operation in which a two-rib flap was used. Many surgeons would to-day treat a case of this type with resection, but even then a space-reducing procedure might well have been needed.

I should perhaps explain that the reason the total $\stackrel{\vec{S}}{\supset}$ number of cases in which I have used the pro- $\vec{\varphi}$ cedure is so small is chiefly because of the great $\mathcal{G}$ change that has occurred in my thoracic surgical work during the last few years.

\section{REFERENCES}

Björk, V. O. (1954). J. thorac. Surg., 28, 194.

Brock, R. C. (1946). Ibid., 15, 182.

Eloesser, L. (1942). Amer. Rev. Tuberc., 45, 703.

Overholt, R. H., and Kenney, L. J. (1951). Surgical Forum. Clinical Congress, American College of Surgeons, 1950, p. 3. Saunders, Philadelphia. 